\title{
Extended stratification assures prompt walnut germination
}

\author{
F. W. VON ALTHEN
}

Canadion Forestry Service

Great Lakes Forest Research Centre Sault Ste. Marie, Ontario

Black walnut (Juglans nigra L.) seed has very pronounced dormancy which may be broken by low temperature stratification (Woody-plant seed manual, USDA Misc. Publ. 654. 416 p.). Nuts either seeded in autumn or stratified over winter and seeded the following spring often germinate over a period of several months and even as late as the spring of the second year. This uncertainty concerning the time required for germination, combined with an average viability of 70 to $80 \%$, has resulted in the general recommendation to sow two or three nuts per seed spot. While this method assures some success, it has serious disadvantages: it is wasteful; it frequently results in the growth of more than one tree per seed spot, requiring subsequent thinning; and it does not adequately compensate for delayed germination, resulting in small, less hardy plants at the end of the growing season.
To develop an efficient and inexpensive method of stratification, a study was initiated in the autumn of 1966 to determine the effects of extended cold stratification on the time required for seedling emergence and on total germination.

Nuts were collected in 1966 , '67 and '68 from a grove of trees near Grand Bend in southern Ontario. After the nuts were hulled and graded by water floatation, they were stored in $241 / 2-\times 17-$ inch galvanized steel garbage cans between 3-inch layers of mo:st sand. No further water was added. Storage temperature was maintained at $32^{\circ} \mathrm{F}$. In lots of 500 , nuts were removed from cold storage after 7 and 19 months for planting in the spring of the first or second year after collection. One lot of 1966 nuts was kept in storage for 31 months. The nuts were seeded immediately in moist sand in a greenhouse where the temperature ranged be-

\section{Application}

The findings presented here should be of direct benefit to tree planters in southern Ontario where walnut grows at the northern limit of its natural range. After stratification in moist sand for 19 months in either a cold room or fresh fruit storage locker, one nut should be seeded in each planting spot in early June. Seeding at this time will avoid frost damage and will allow sufficient time for intensive site preparation and will provide adequate time for the emerging seedlings to become firmly established before the advent of the usual summer drought. All seed spots not stocked 3 weeks after planting should be reseeded with pregerminated nuts from the original lot.

tween $72^{\circ} \mathrm{F}$ and $85^{\circ} \mathrm{F}$. Germination was recorded at weekly intervals for 12 weeks, at which time all nuts that had not germinated were opened and their internal condition recorded. The only exceptions were the nuts from the 1968 crop that had not germinated after 12 weeks in the seedbed following stratification for 7 months. They were stratified intact in cold storage for an additional 9 months.

Sixty-nine to $81 \%$ of all nuts stratified for 19 months germinated within three weeks of seeding, but only 10 to $25 \%$ of the nuts, stratified for 7 months, had germinated after 12 weeks. When the nuts of the 1968 crop which had not germinated after 12 weeks in the seedbed, following stratification for 7 months, were given an additional 9 months stratification, $81 \%$ germinated within 3 weeks. Many of the nuts stratified for 31 months had germinated in cold storage and started to rot in the seedbed. Total germination of this lot was $57 \%$. 